\title{
Impairment of lachrymal and salivary secretion
cellular immune responses to salivary antigens in rheumatoid arthritis
}

\author{
S. SUllivan, L. FERNANDES, I. G. MCFARLANE, B. WOJCICKA, \\ A. L. W. F. EDDLESTON, D. DONIACH, E. HAMILTON, AND ROGER \\ WILLIAMS \\ From the Liver Unit and Department of Rheumatology, King's College Hospital and Medical School, \\ Department of Immunology, Middlesex Hospital, London
}

SUMMARY During a systematic investigation of 100 unselected outpatients with rheumatoid arthritis, 58 were found to have reduced lachrymal or salivary secretion. No correlation could Be detected between the presence or absence of secretory abnormalities and the age or sex of the patient, the presence of nodules or salivary duct antibody, or the occurrence of vasculitis. However, there was a significant correlation between diminished salivary or lachrymal flow and the occurren?e of cellular immune responses to a protein fraction of normal human saliva, sensitisation bei found in $94 \%$ of those with impairment of salivary and lachrymal secretion as compared with $33 \%$ of those without.

The sicca syndrome (xerostomia or keratoconjunctivitis sicca, or both) is a frequent accompaniment of many autoimmune diseases. When specifically sought, sicca features have been found in scleroderma (Alarcon-Segovia et al., 1974a), polyarteritis nodosa (Ramage and Kinnear, 1956), systemic lupus erythematosus (Alarcon-Segovia et al., 1974b), and rheumatoid arthritis (Thompson and Eadie, 1956), as well as in certain liver diseases, particularly chronic active hepatitis and primary biliary cirrhosis (Golding et al., 1973). Most of these conditions are thought to have an autoimmune origin and the secretory abnormalities of the lachrymal and salivary glands are presumed to arise from immunological damage to these glands. The exact nature of the responsible immune reaction has not been elucidated but both humoral (Bertram and Halberg, 1964; MacSween et al., 1967; Feltkamp and van Rossum, 1968) and cellular (Søberg and Bertram, 1968; Berry et al., 1972; Anderson et al., 1973) mechanisms have been suggested. In the present study, humoral and cellular immune responses to salivary antigens were examined in relation to clinical and subclinical impairment of salivary and lachrymal function in 100 unselected patients with rheumatoid arthritis.

Accepted for publication August 8, 1977

Correspondence to Dr R. Williams, Liver Unit, King's College Hospital, Denmark Hill, London SE5 9RS

\section{Patients and methods}

100 outpatients with definite or classical rheumatood arthritis (according to the criteria of the American Rheumatoid Association) were evaluated. 92 patien were being treated with nonsteroidal anti-inflammatory drugs, 30 with corticosteroids, 31 wi penicillamine, and 11 were receiving gold therapy. Patients on cytotoxic therapy were not included 跑 the study. The patients were specifically questionge about symptoms of dry mouth and dry or grity eyes. Tear flow was assessed by the Schirmer tes. Patients in whom there was less than $5 \mathrm{~mm}$ moistening of the filter paper strips in both eyes aftero5 minutes were regarded as having xerophthalmig. 14 normal subjects tested under identical conditions all showed greater than $20 \mathrm{~mm}$ moistening of th filter paper strips. At the time of testing all patients were adequately hydrated and were not receiving any drugs known to affect lachrymal functions. Rose-Bengal staining was performed by introduciag a $1 \%$ aqueous solution of the dye into the conjunctivyl sac followed immediately by irrigation with norms saline. Eyes were then examined for corneal or conjunctival staining using a Haag-Streit slit-lamp Total saliva flow was measured by spitting intoaa beaker all saliva produced in 10 minutes whipe chewing mint-flavoured gum. A diagnosis बff xerostomia was made when the total salifa 
production was less than $12 \mathrm{ml} / 10$ minutes $(2 \mathrm{SD}$ below the mean for 20 normal subjects). Severity of arthritis was assessed by the articular index, grip strength, duration of morning stiffness, and the presence of nodules or vasculitis.

Laboratory investigations included haemoglobin concentration, white blood cell count, erythrocyte sedimentation rate, total serum globulins, and rheumatoid factor. Antinuclear and gastric parietal cell antibodies were detected by immunofluorescence while antithyroid antibodies were detected by immunofluorescence and tanned red cell agglutination.

\section{HUMORAL AND CELLULAR}

\section{ANTISALIVA IMMUNE RESPONSES}

Antisalivary duct antibody was detected by indirect immunofluorescence of undiluted plasma on human submaxillary gland. Cell-mediated immunity to a salivary antigen preparation was evaluated in 32 patients and 20 controls by the leucocyte migration test (Mitchell et al., 1972). Salivary antigen, prepared from normal human saliva by ammonium sulphate fractionation, was used in the leucocyte migration test at a concentration of $50 \mu \mathrm{g} / \mathrm{ml}$ (McFarlane $e t$ al., 1976). Measurements of migration indices in the normal subjects gave a range of 0.74 to 1.02 (mean \pm SD). Indices which fell below or above these limits were regarded as significant inhibition or stimulation of migration respectively.
Student's $t$ test or $\chi^{2}$ test with Yates's correction (where appropriate) were used for statistical analyses.

\section{Results}

Fifty-eight of the 100 patients showed evidence of diminished salivary or lachrymal function (Table). 18 patients had xerostomia, 26 had xerophthalmia, and 14 had both. As part of a separate study, 32 of these patients were also investigated using the Rose-Bengal test. $11(65 \%)$ of 17 patients with diminished tear flow were found to have positive Rose-Bengal staining. By comparison, all of the remaining 15 who had normal Schirmer's tests were also normal on slit-lamp examination.

Only 19 of those with secretory abnormalities admitted to having dry eyes or mouths and these symptoms were as common in those with apparently normal secretion. Similarly, there were no apparent differences between those with and without impairment of secretion with respect to age, sex, duration or severity of disease, occurrence of vasculitis, or the presence of nodules; nor did they differ with respect to haemoglobin, white cell count, erythrocyte sedimentation rate, total globulins, presence of autoantibodies, or rheumatoid factor.

\section{HUMORAL IMMUNITY}

Salivary duct antibodies were detected in 26 patients (Table). A comparison of those with and without

Table Comparison of clinical and laboratory data of patients with and without xerostomia/xerophthalmia and salivary duct antibody

\begin{tabular}{|c|c|c|c|c|}
\hline & \multicolumn{2}{|c|}{ Xerostomia or xerophthalmia } & \multicolumn{2}{|c|}{ Salivary duct antibody } \\
\hline & $\begin{array}{l}\text { Present } \\
(n=58)\end{array}$ & $\begin{array}{l}\text { Absent } \\
(n=42)\end{array}$ & $\begin{array}{l}\text { Present } \\
(n=26)\end{array}$ & $\begin{array}{l}\text { Absent } \\
(n=74)\end{array}$ \\
\hline $\begin{array}{l}\text { Male: female ratio } \\
\text { Age (years) } \\
\text { Duration of arthritis (years) } \\
\text { Xerostomia or xerophthalmia }\end{array}$ & $\begin{array}{l}20: 38 \\
59 \pm 10 \\
13 \pm 11\end{array}$ & $\begin{aligned} 13 & : 29 \\
57 & \pm 10 \\
9 & \pm 9\end{aligned}$ & $\begin{array}{l}11: 15 \\
60 \pm 8 \\
10 \pm 10\end{array}$ & $\begin{array}{l}22: 52 \\
58 \pm 11 \\
12 \pm 10\end{array}$ \\
\hline $\begin{array}{l}\text { Symptoms } \\
\text { Signs }\end{array}$ & $11 \quad(19 \%)$ & $8 \quad(19 \%)$ & $\begin{aligned} 6 & (23 \%) \\
12 & (46 \%)\end{aligned}$ & $\begin{array}{ll}12 & (16 \%) \\
46 & (62 \%) \\
\chi^{2}= & 2 \cdot 73\end{array}$ \\
\hline $\begin{array}{l}\text { Morning stiffness }(\mathrm{h}) \\
\text { Articular index } \\
\text { Grip strength }(\mathrm{mmHg})\end{array}$ & $\begin{array}{l}0.64 \pm 0.62 \\
9 \pm 5 \\
107 \pm 72\end{array}$ & $\begin{array}{l}0 \cdot 70 \pm 0 \cdot 72 \\
9 \pm 7 \\
99 \pm 62\end{array}$ & $\begin{array}{l}0.69 \pm 0.67 \\
9 \pm 5 \\
93 \pm 55\end{array}$ & $\begin{array}{l}0.69 \pm 0.71 \\
9 \pm 5 \\
107 \pm 70\end{array}$ \\
\hline $\begin{array}{l}\text { Nodules } \\
\text { Vasculitis }\end{array}$ & $\begin{array}{l}13(22 \%) \\
2\end{array}$ & $\begin{array}{l}12(29 \%) \\
1\end{array}$ & $8(31 \%)$ & $\begin{array}{l}17(23 \%) \\
2\end{array}$ \\
\hline $\begin{array}{l}\text { Haemoglobin }(\mathrm{g} / \mathrm{dl}) \\
\text { White blood count }\left(\times 10^{9} / \mathrm{l}\right)\end{array}$ & $\begin{array}{l}12 \cdot 9 \pm 1 \cdot 4 \\
7 \cdot 9 \pm 1 \cdot 9\end{array}$ & $\begin{array}{l}12 \cdot 8 \pm 1 \cdot 4 \\
8 \cdot 1 \pm 1 \cdot 9\end{array}$ & $\begin{array}{l}12 \cdot 8 \pm 1 \cdot 6 \\
8 \cdot 8 \pm 1 \cdot 5\end{array}$ & $\begin{array}{l}12 \cdot 8 \pm 1 \cdot 3 \\
7 \cdot 7 \pm 1 \cdot 9 \\
P<0 \cdot 01\end{array}$ \\
\hline $\begin{array}{l}\text { ESR }(\mathrm{mm} / \mathrm{h}) \\
\text { Globulin }(\mathrm{g} / \mathrm{l})\end{array}$ & $\begin{array}{l}40 \pm 26 \\
34 \pm 7\end{array}$ & $\begin{array}{l}40 \pm 30 \\
32 \pm 6\end{array}$ & $\begin{array}{l}44 \pm 28 \\
35 \pm 6\end{array}$ & $\begin{array}{l}39 \pm 27 \\
32 \pm 6\end{array}$ \\
\hline Rheumatoid factor & $39^{-}(67 \%)$ & $28 \quad(67 \%)$ & $20 \quad(77 \%)$ & $4764 \%)$ \\
\hline Antinuclear antibody & $8 \quad(14 \%)$ & $\begin{array}{l}11(26 \%) \\
x^{2}=3 \cdot 30\end{array}$ & $6 \quad(23 \%)$ & $13(18 \%)$ \\
\hline Antithyroid antibody & $14(24 \%)$ & $8 \quad(19 \%)$ & $9 \quad(25 \%)$ & $\begin{array}{l}13(18 \%) \\
\chi^{2}=2 \cdot 34\end{array}$ \\
\hline Parietal cell antibody & $5 \quad(9 \%)$ & $4 \quad(10 \%)$ & $6 \quad(23 \%)$ & $\begin{array}{l}3 \quad(4 \%) \\
x^{2}=6 \cdot 33\end{array}$ \\
\hline Salivary duct antibody & $12(21 \%)$ & $\begin{array}{l}14(33 \%) \\
\chi^{2}=2 \cdot 73\end{array}$ & & \\
\hline
\end{tabular}

Note: Means \pm SD given where applicable or number of patients with percentages of total numbers in parentheses. 
salivary duct antibody showed no difference with respect to age, sex, duration or severity or arthritis. The white blood count in those patients with the antibody was significantly higher than in those without $\left(8.8 \pm 15 \times 10^{9} / 1\right.$ compared with $\left.7 \cdot 7 \pm 1.9 \times 10^{9} / 1\right)$, but this difference could not be explained. Surprisingly, no correlation could be detected between the presence of salivary duct antibody and the occurrence or severity of xerostomia or xerophthalmia. There was, however, a statistically significant association between salivary duct antibodies and the presence of gastric parietal cell antibodies $(P<0.025)$. The frequency of antithyroid antibodies was also increased in those patients with salivary duct antibodies, but this increase was not statistically significant.

\section{CELLULAR IMMUNITY}

Inhibition of leucocyte migration in response to the salivary antigen was observed in 13 and stimulation in 3 of 17 patients with impaired secretion (Fig.). By comparison, inhibition was found in only 4 and stimulation in 1 of 15 patients with apparently

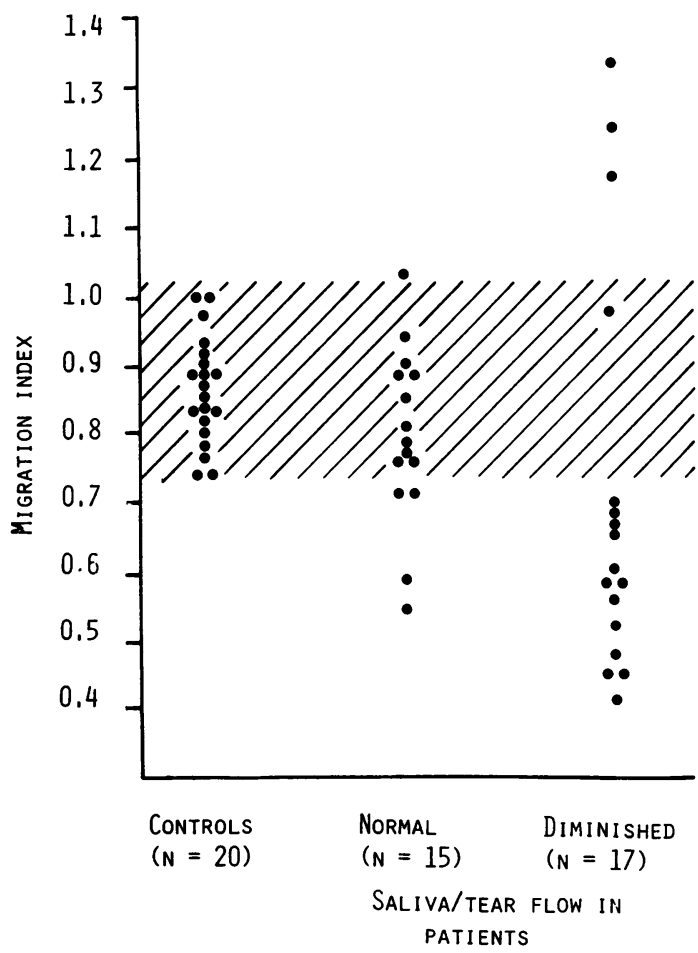

Fig. Results of leucocyte migration test using salivary' antigen in control subjects and in patients with normal or diminished saliva or tear flow. Hatched area shows the normal range (mean $\pm 2 S D$ of indices in normal subjects). normal secretions. The difference between thoș with and those without secretory abnormalities ofs statistically significant, whether inhibition alome $\left(\chi^{2}=6.06, P<0.025\right)$ or both inhibition stimulation $\left(\chi^{2}=10.4, P<0.005\right)$ are regarded gs indicative of cellular hypersensitivity. Sensitisation did not appear to be dependent upon whether the impairment of secretion was salivary or lachrym.

\section{Discussion}

The finding that $58 \%$ of our patients had abnormgl Schirmer's tests or reduced saliva flow indicates the impaired salivary or lachrymal secretion occurs fir more frequently in rheumatoid arthritis than the symptoms of dry eyes or dry mouths might suggest. Indeed, only $19 \%$ of our patients with xerostomia or xerophthalmia had suggestive symptoms af these were as common in those with secretory impairment as in those without. A similar poar correlation of symptoms with objective measure ments has been noted by MacSween et al. (1967).

While a diagnosis of keratoconjunctivitis sicka cannot be made only on the results of a Schirmers test, it is of interest that 11 of 17 patients with abnormal Schirmer's tests also had positive RosBengal staining. This finding indicates that the Schirmer's test is a reliable method of screening for keratoconjunctivitis sicca, particularly when the criterion of abnormality is $5 \mathrm{~mm}$ rather than the customary $10 \mathrm{~mm}$ moistening of the filter paper strips in 5 minutes. Moreover, since in the complete series 40 patients were diagnosed as having xerop亜thalmia, these findings suggest that keratocơnjunctivitis sicca may be much more common oin rheumatoid arthritis than the frequently quoted figure of $14.3 \%$ (Thompson and Eadie, 195\%), although fortunately the abnormalities are often not sufficiently severe to cause clinical symptoms.

In contrast to other studies, we did not find that impaired secretion was more common in womon than in men (Bloch et al., 1965) and there seemedfo be no correlation with the severity or duration $\rightarrow f$ the rheumatoid disease or with associated immunglogical features such as rheumatoid factor (Whaley et al., 1973). Similarly, salivary duct antibody was no more common in rheumatoid arthritis with xerostomia or xerophthalmia than in rheumate arthritis alone. This suggests that the production of salivary duct antibodies is not primarily related $\overline{\$ 0}$ the development of xerostomia but merely reflects the propensity of some of these patients to produ?e autoantibodies (Whaley et al., 1969). This is supported by the finding of a significantly greater incidence of gastric parietal cell antibodies in those patients with salivary duct antibodies. 
The only immunological factor which distinguished the patients with impaired lachrymal or salivary secretion was the finding of cellular immune responses to salivary antigens in $94 \%$ of these cases. The finding of sensitisation to salivary antigens in $33 \%$ of patients with apparently normal salivary and lachrymal secretion is not surprising. Both the Schirmer's test and saliva flow measurements are relatively insensitive measures of glandular function and the immunological abnormalities would be expected to occur before secretory abnormalities become demonstrable. Indeed, Berry et al. (1972) have documented progression to clinically detectable keratoconjunctivitis sicca in a small number of asymptomatic patients with antisalivary gland cellmediated immunity.

The occurrence of cellular immune responses to salivary gland antigens in patients with the sicca syndrome has also been found by Søberg and Bertram (1968) and is in accordance with the demonstration of a periductular lymphocytic infiltrate in the affected glands (Chisholm and Mason, 1968; Anderson et al., 1973). The exact nature of the target antigen(s) is obscure because these investigators have used relatively crude extracts of whole salivary glands. In this study we have used a partially purified protein fraction of normal human saliva which we have previously shown (McFarlane et al., 1976) contains at least four antigens, two of which are also present in homogenates of whole salivary glands. Whether one of these antigens is derived from the salivary duct epithelium will remain unknown until the relevant antigens have been further purified.

We are grateful to the Wellcome Trust for their continued support, to Peggy Henderson for clinical assistance, and to Linda Rimmer for editorial help. S.S. was supported by a McLaughlin Fellowship.

\section{References}

Alarcon-Segovia, D., Ibanez, G., Hernandez-Ortiz, J., Velazquez-Forero, F., and Gonzalez-Jimenez, Y. (1974a). Sjögrens syndrome in progressive systemic sclerosis (scleroderma). American Journal of Medicine, 57, 78-85.

Alarcon-Segovia, D., Ibanez, G., Velazquez-Forero, F., Hernandez-Ortiz, J., and Gonzalez-Jimenez, Y. (1974b). Sjögren's syndrome in systemic lupus erythematosus: clinical and subclinical manifestations. Annals of Internal Medicine, 81, 577-583.
Anderson, L. G., Tarpley, T. M., Talal, N., Cummings, N. A., Wolf, R. O., and Schall, G. L. (1973). Cellularversus-humoral autoimmune responses to salivary gland in Sjögren's syndrome. Clinical and Experimental Immunology, 13, 335-342.

Berry, H., Bacon, P. A., and Davis, J. D. (1972). Cellmediated immunity in Sjögren's syndrome. Annals of the Rheumatic Diseases, 31, 298-302.

Bertram, U., and Halberg, P. (1964). A specific antibody against the epithelium of the salivary ducts in sera from patients with Sjögren's syndrome. Acta Allergologica, 19, 458-466.

Bloch, K. J., Buchanan, W. W., Wohl, M. J., and Bunim, J. J. (1965). Sjögren's syndrome. A clinical, pathological, and serological study of 62 cases. Medicine, 44, 187-231.

Chisholm, D. M., and Mason, D. K. (1968). Labial salivary gland biopsy in Sjögren's disease. Journal of Clinical Pathology, 21, 656-660.

Feltkamp, T. E. W., and van Rossum, A. L. (1968). Antibodies to salivary duct cells and other autoantibodies in patients with Sjögren's syndrome and other idiopathic autoimmune diseases. Clinical and Experimental Immunology, $3,1-16$.

Golding, P. L., Smith, M., and Williams, R. (1973). Multisystem involvement in chronic liver disease. Studies on the incidence and pathogenesis. American Journal of Medicine, 55, 772-782.

McFarlane, I. G., Wojcicka, B. M., Tsantoulas, D. C., Funk, C., Portmann, B., Eddleston, A. L. W. F., and Williams, R. (1976). Cellular immune responses to salivary glands in autoimmune liver disease with sicca syndrome. Clinical and Experimental Immunology, 25, 389-395.

MacSween, R. N. M., Goudie, R. B., Anderson, J. R., Armstrong, E., Murray, M. A., Mason, D. K., Jasani, M. K., Boyle, J. A., Buchanan, W. W., and Williamson, J. (1967). Occurrence of antibody to salivary duct epithelium in Sjögren's disease, rheumatoid arthritis and other arthritides. A clinical and laboratory study. Annals of the Rheumatic Diseases, 26, 402-411.

Mitchell, C. G., Smith, M. G. M., Golding, P. L., Eddleston, A. L. W. F., and Williams, R. (1972). Evaluation of the leucocyte migration test as a measure of delayed hypersensitivity in man: suppression of migration inhibition of puromycin. Clinical and Experimental Immunology, 11, 535-541.

Ramage, J. H., and Kinnear, W. F. (1956). Kerato conjunctivitis sicca and the collagen diseases. British Journal of Ophthalmology, 40, 416-423.

Søberg, M., and Bertram, U. (1968). Cellular hypersensitivity in Sjögren's syndrome. Acta Medica Scandinavica, 184, 319-327.

Thompson, M., and Eadie, S. (1956). Kerato conjunctivitis sicca and rheumatoid arthritis. Annals of the Rheumatic Diseases, 15, 21-25.

Whaley, K., Chisholm, D. M., Goudie, R. B., Downie, W. W., Dick, W. C., Boyle, J. A., and Williamson, J. (1969). Salivary duct autoantibody in Sjögren's syndrome. Correlation with focal sialodenitis in the labial mucosa. Clinical and Experimental Immunology, 4, 273-281.

Whaley, K., Webb, J., McAvoy, B. A., Hughes, G. R. V., Lee, P., MacSween, R. N. M., and Buchanan, W. W. (1973). Sjögren's syndrome. 2. Clinical associations and immunological phenomena. Quarterly Journal of Medicine. 42, 513-548. 